\title{
A Valorização da Gastronomia Tradicional na Mafalala e o Seu Impacto no Turismo da Cidade de Maputo
}

https://doi.org/10.21814/uminho.ed.48.17

\author{
Alda Damas \\ Instituto de Investigação Sócio-Cultural (ARPAC), Maputo, Moçambique \\ aldadamas@yahoo.com \\ Célia Mazuze \\ Instituto de Investigação Sócio-Cultural (ARPAC), Maputo, Moçambique \\ cmazuze@yahoo.com.br
}

\section{Resumo}

O artigo tem como objectivo reflectir sobre a necessidade da valorização da gastronomia tradicional na Mafalala como estratégia de desenvolvimento local. Desta forma, analisamos a importância do turismo gastronómico e a sua operacionalização como forma de promoção do desenvolvimento local. Com base nos dados do inventário trazemos uma proposta de pratos e bebidas a serem explorados e valorizados no contexto turístico da cidade de Maputo (badjia, xibubutela, xiginya xa nkakana, tihove, mathapa, nimino de mandioca, karakata, nkakana, wuputsu, ukanyi, etc.). Em termos metodológicos, o artigo baseou-se, em grande parte, nos resultados do Inventário Comunitário do Património Cultural Imaterial, realizado em agosto de 2016 no bairro da Mafalala, e na revisão bibliográfica, para suporte teórico e contextualização do tema em análise. Com esta pesquisa, espera-se contribuir para a projecção da dimensão histórica, cultural e turística, por via dos sabores e aromas das iguarias locais que, por um lado, reflectem a propalada diversidade do bairro e, por outro, alimentam a possibilidade de a comunidade, sobretudo as mulheres obterem rendimento com o turismo.

\section{Palavras-chave}

Mafalala, identidade, património cultural imaterial, turismo gastronómico 


\section{Introdução}

O presente trabalho foi gerado a partir de uma experiência de campo, aquando da realização do Inventário do Património Cultural Imaterial (PCI), no bairro da Mafalala, em agosto de 2016. Para além de trazer uma reflexão teórica sobre o tema, sugere, igualmente, acções de intervenção, com impacto na renda da comunidade.

Durante o processo de inventariação, tivemos a oportunidade de apreciar e degustar deliciosos sabores da cozinha tradicional moçambicana, em algumas residências por onde passámos, isso quando fôssemos convidados, porque quando não, consumíamos o que era possível encontrar à venda nos restaurantes, barracas ${ }^{1}$ e arredores, especificamente: frango, batata frita, wors, salgados, guisados, grelhados, entre outros.

Cansados de alimentarmo-nos com este tipo comidas, questionámos aos guias se existia um lugar na Mafalala onde se podia degustar sabores tradicionais, dado que, o que está mais exposto são pratos "estranhos" à realidade gastronómica local, o que simboliza marcas de um consumismo que atenta à sobrevivência da culinária tradicional.

Foi com base nestas constatações que surgiu a seguinte questão de partida: em que medida a valorização da gastronomia tradicional moçambicana, representada na Mafalala, pode contribuir para o desenvolvimento do turismo cultural no bairro e na cidade de Maputo, em geral?

Mafalala é um destino turístico com um grande potencial gastronómico (badjias, mahanti, mahaza, tifiyose, xibubutela, xiginya xa nkakana, tihove, karakata, xima, nkakana, mathapa, nyangana, mbowa, frango à zambeziana, mahewu, wuptsu, ukany, xilalasana, etc.), que reflecte a diversidade cultural do país. No entanto, apesar deste potencial gastronómico, nota-se, ao que nos parece, um fraco aproveitamento e incentivo nesta área, tendo em conta que a gastronomia constitui um grande atractivo do turismo cultural.

Nesse sentido, o intuito deste trabalho é refletir sobre a necessidade da valorização da gastronomia tradicional na Mafalala, como estratégia de desenvolvimento local. Desta forma, analisamos a importância do turismo gastronómico e a sua operacionalização como forma de promover o desenvolvimento local. Com base nos dados do inventário trazemos uma proposta de pratos e bebidas a serem explorados e valorizados no contexto turístico (hotéis, restaurantes, bares, lanchonetes, barracas, etc.) da cidade de Maputo.

Em termos metodológicos, este artigo foi elaborado com base nos resultados do Inventário Comunitário do Património Cultural Imaterial da Mafalala (PCI), decorrido em agosto de 2016, o qual consistiu na realização de entrevistas semi-estruturadas, com vários actores ligados aos diferentes grupos socioculturais do bairro (macua, 
rhonga, chope, bitonga, comoreanos, etc.). Na mesma ordem, efectuou-se a pesquisa bibliográfica para obtenção do suporte teórico e contextualização do tema em análise. Este processo suscitou não somente o levantamento das iguarias locais, mas também da história, mitos e crenças, associados à gastronomia tradicional destes grupos.

\section{Identidade Gastronómica Como AtractivoTurístico}

$\mathrm{Na}$ lógica da actividade turística, onde a diferença e as especificidades de um local são matéria-prima básica para diferenciação de um destino turístico em relação ao outro, os aspectos identitários tornam-se num importante atractivo, face a um mercado globalizado e altamente competitivo, que busca cada vez mais a diferenciação dos seus produtos.

Neste sentido, a oferta gastronómica de uma região, assume-se como o mais proeminente ponto de diferenciação cultural, tendo em vista que os hábitos alimentares de um povo e os seus modos de fazer expressam a sua identidade. Falando sobre os hábitos alimentares, Franco Ariovaldo (2003) defende que estes não decorrem apenas do instinto de sobrevivência e das necessidades do indivíduo se alimentar. São, portanto, expressões de uma história, geografia, clima, organização social, crenças religiosas, entre outros. Já o gosto, que muita gente acredita ser próprio, é também moldado culturalmente e socialmente controlado (Ariovaldo, 2003, p. 24).

Debruçando-se ainda a respeito da alimentação e cultura, Bonin e Rolim (1991, como citados em Gândara et al., 2009) argumentam que "os hábitos alimentares se traduzem na forma de seleção, preparo e ingestão de alimentos, que não são o espelho, mas se constituem na própria imagem da sociedade" ( $p .181$ ).

E porque a alimentação constitui a imagem da sociedade, ela desperta inúmeras curiosidades aos turistas, dada sua capacidade não só de proporcionar prazeres palatais, como também de acrescentar ao indivíduo conhecimentos culturais e status social. A título de exemplo, o consumo de caviar beluga pode indicar status social. A ausência de porco no cardápio dos islâmicos e judeus pode indicar religião, assim como a maneira de preparar e a forma de servir e de repartir o alimento expressa a organização social dos valores morais e a divisão do trabalho.

No que concerne à alimentação como fonte de conhecimento, Poulain (2002/2013) refere que "a alimentação tem uma função estruturante da organização social de um grupo humano, quer se trate de distribuição, de preparação, de consumo ela é um objecto crucial do saber socioantropológico" (p.285), pois, através da alimentação, podemos identificar uma sociedade, uma cultura, uma religião, um estilo de vida, uma classe social, um acontecimento ou uma época, com diz a celebre frase do gastrónomo francês Brillat-Savarin "diz-me o que comes dir-te-ei quem és", patente na sua obra intitulada A Filosofia do Gosto, lançada em 1825.

Deste modo, o turista ao consumir a gastronomia local acaba valorizando-a e, ao mesmo tempo, desperta interesse aos habitantes, que passarão a ter orgulho de 
suas raízes, recuperando assim parte da sua história e cultura imaterial associada à gastronomia tradicional. Como sugerem Frandrin e Montonari (1996, como citados em Müller \& Amaral, 2012), "a gastronomia tradicional atua na valorização da cultura regional, na perpetuação da memória culinária das famílias e oferece ganhos de recursos económicos, tanto para a indústria como para o comércio local” (p. 4).

Como se pode depreender, existem várias razões pelas quais uma região ou localidade, detentora de património gastronómico, independentemente do seu maior ou menor reconhecimento, como destino turístico, deve apostar na promoção e divulgação da qualidade e diferenciação dos seus produtos. Conforme dita a lógica da actividade turística, pois, como afirma Gimenes (2006), "quanto mas diferenciado, mais "típico" for o prato, mas valorizado ele será" conforme dita a lógica da atividade turística (p. 5).

\section{Turismo Gastrónomico}

Turismo gastronómico é um segmento do turismo cultural, no qual o deslocamento de visitantes se dá por motivos vinculados às práticas gastronómicas de uma determinada localidade (Gândara et al., 2009).

Para melhor compressão do turismo gastronómico é importante definir, inicialmente, o conceito de gastronomia, objecto da nossa pesquisa. Segundo o Glossário de Gastronomia e Culinária (2009, como citado por Costa, 2009),

a gastronomia é a arte culinária que compreende os métodos, as técnicas e procedimentos destinados a transformar e sazonar os alimentos da sua forma hóstil e bruta como a natureza nos apresenta e apresentá-los de maneira que constituam um prazer ao paladar, à vista e ao aroma. (p. 67)

Como se pode depreender pela definição, a prática gastronómica abrange um rico universo de bens culturais de natureza material (os alimentos em si e os utensílios culinários) e imaterias (técnicas de preparo, rituais relacionados à degustação, representações do próprio alimento, saberes, etc.), associados à identidade de um povo.

Como actividade, o turismo gastronómico já vem sendo desenvolvido com sucesso há bastante tempo na Europa, mas a sua nomenclatura, de acordo com Long (2004, como citado em Costa, 2009), só foi adquirida no final dos anos 1990, alicerçada ao preceito do desenvolvimento sustentável, um conceito que emerge, segundo Santana (2016), por volta da década 1980, como resposta à massificação da actividade turística e das consequências que esta gera.

Considera-se que no passado, no início dos empreendimentos turísticos na Europa, concretamente durante o século XVII, a alimentação aparecia apenas como uma necessidade biológica - os viajantes burgueses pouco se interessavam pela culinária popular do destino, sua atenção estava mais voltada para as paisagens. Todavia, a partir da primeira metade do século XX, o olhar dos viajantes se modifica, 
influenciados por vários factores, entre os quais a expansão das linhas férreas e dos guias turísticos. Como descreve Santana (2016):

é nos anos 1840 que surgem no continente europeu, com a expansão das estradas de ferro, os guias turísticos. A gastronomia começa a aparecer de forma mais sistemática com as especialidades alimentares locais, mas não faz parte ainda da economia turística. Isso ocorre apenas nos anos de 1920. (p. 49)

Com a expansão das linhas férreas e do parque automobilístico, as empresas passam a explorar mais as regiões e as especialidades culinárias. Estas juntaram-se a outras representações estereotipadas do "local", os guias turísticos. Sob esta perspectiva, em 1920, o Guia Michelin lança uma edição na França na qual aparecem os primeiros conselhos gourmet ${ }^{2}$. Entre 1930 e 1950, vários guias dedicados ao turismo gastronómico relançam receitas das suas províncias com itinerários, rotas, passeios e excursões que fazem da gastronomia local uma ponte essencial da experiência turística. A título de exemplo, temos o Guide Bleu Bords de Loure et Sud, lançado em 1930 (que tinha como especialidade gastronómica os principais vinhos de cada região da França) e o Guia Gastronómico d'Italia, lançado em 1931 pela empresa de transporte Touring Club (Santana, 2016; Silva, 2013).

Por sua vez, os hotéis e restaurantes esforçavam-se em preservar e promover as cozinhas regionais e as receitas de família e o know how local, com desejo de atrair novos clientes e estimular a economia local (Silva, 2013). Na mesma lógica, alguns países na Europa, visionando o futuro do turismo gastronómico, começaram a desenvolver nos seus territórios políticas de incentivo ao consumo dos produtos locais e regionais, como aquela que se verificou na Itália, por volta da primeira metade do século XX.

Em 1931, o fascismo encorajava o consumo de produtos nacionais, através de uma política alimentar denominada autárquia, e relança a visita das regiões italianas graças a uma rede ferroviária que permite viajar um pouco por todos os lados, criando, dessa forma, no Norte, um novo tipo de mobilidade. (Capatti, 2006, p. 20)

Desta forma, a gastronomia passa a ser usada como marca de identidade nacional, a partir de um discurso oficial, que se apoia na cultura alimentar para construir o regionalismo. E, deste jeito, cresce, igualmente, o discurso da tipicidade e do terroir ${ }^{3} \mathrm{e}$ o fenómeno da patrimonialização da alimentação ganha força.

20 conceito gourmet refere-se a um estilo de culinária mais elaborada, requintada, e que atende às exigências do consumidor com gosto mais apurado em relação à qualidade e apresentação do prato ou da bebida.

3 Terroir, termo referente a toda a característica climática de um lugar, propriedade do solo, que torna o local único, produzindo assim, alimentos únicos em sua característica. Inicialmente esta palavra era usada para vinicultura, porém, hoje em dia o seu uso ampliou para outros alimentos. Actualmente a expressão terroir designa um produto de uma área limitada (Müller \& Amaral, 2012, p. 4). Segundo Poulain (2002/2013), o conceito terroir, diz respeito à relação entre o indivíduo e a natureza e a tipicidade exige o respeito à estrutura da refeição - mesmo que esse modelo seja uma invenção recente. 
Com a crescente internacionalização da indústria agroalimentar (pizzarias, fast food, etc.), e a uniformidade dos campos de cultivo na Europa devido à seca e à agressão da gastronomia, surge na Itália, por volta de 1986, um novo modelo turístico aliado à alimentação, o slow food ${ }^{4}$, em oposição ao modo de vida apresentado pelo fast food . $^{\text {. }}$ Este movimento valoriza os pequenos produtores locais, as tradições alimentares e toda a cadeia produtiva do alimento, do campo à mesa (Santana, 2016).

A nível mundial, muitos países têm procurado promover e valorizar os produtos e cozinhas das suas províncias ou localidades. Tomamos como exemplo a Festa da Cerveja, realizada na Alemanha, na cidade de Munique; a Festa da Uva, realizada no Brasil, na cidade Caxias do Sul, no estado do Rio Grande do Sul; o Circuito do Vinho, em Portugal, com 12 rotas registradas e duas em formação.

Em Moçambique, este tipo de turismo, cuja motivação é essencialmente gastronómica, segue a passos lentos. Alguns exemplos desta modalidade de turismo no país são: as feiras agropecuárias que o Ministério da Agricultura e Segurança Alimentar tem desenvolvido em alguns distritos; os festivais gastronómicos, como o Festival Ekhala (carangueijo), introduzido recentemente (2016) em Nacala-à-Velha, na província de Nampula; o Festival do Camarão, realizado na cidade de Quelimane e no distrito de Marromeu, nas provínciais da Zambézia e de Sofala, respetivamente; o Festival Nyama (da carne) e a Feira do Boi, no distrito de Magude, na província de Maputo; e o mais recente (2018), o Festival Tzotiva (vários sabores), realizado na Itha de Moçambique, província de Nampula; os mercados municipais e feiras, como, por exemplo, o Mercado do Peixe e a Feira de Artesanato, Flores e Gastronomia de Maputo, na cidade de Maputo.

\section{Reflexão Sobre a Necessidade da Valorização da Gastronomia Tradicional na Mafalala}

Mafalala é um bairro periférico da cidade de Maputo. Surgiu com a expansão da cidade de Lourenço Marques, actual Maputo, num contexto de segregação racial e espacial imposta pelo regime colonial ${ }^{6}$. A procura de emprego e melhores condições de vida aumentou o fluxo da população um pouco de todos os cantos do país para este bairro, destacando-se os povos islâmicos da costa, entre os quais macuas, que se juntaram à população autóctone (rhonga). Deste encontro de culturas abriu-se espaço para o surgimento de novos sabores, que hoje se encontram intricados às práticas gastronómicas deste povo. Portanto, falar de Mafalala é falar de Moçambique em miniatura.

\footnotetext{
4 Nascido sob o nome de "arcigola" e fundado em 1986, no Piemote (Itália), por Carlos Petrini, slow food se torna internacional em 1989, como "movimento pela tutela e pelo direito ao prazer" (alimento bom, limpo e justo). O slow food opõe-se ao fast food promovendo o prazer de saborear boa comida e de qualidade (Weiner, 2005).

50 fast food, que literalmente significa "comida rápida", é originário dos Estados Unidos. 0 modelo foi inovado, comercializado e difundido por empresas transnacionais em grandes redes de franquias como a McDonald's (Oliveira \& Freitas, 2008).

6 Mafalala é também o espaço que viu nascer e crescer várias personalidades: das áreas das artes, José Craverinha e Noémia de Sousa; do desporto, Eusébio da Silva e Ricardo Chibanga; da política, Joaquim Alberto Chissano e Pascoal Mucumbi, entre outras.
} 
Esta diversificada gastronómica é também fruto da influência de asiáticos, europeus e povos de outras regiões de África. A badjia, por exemplo, é prova disso, embora a sua origem esteja associada à Índia, cuja designação é bhajji, feita com a farinha de grão-de-bico. Em Moçambique, este grão-de-bico foi substituído por feijão nhemba (timbawene em rhonga), cientificamente conhecido por Vegna unguiculata, muito comum em África, dada a sua capacidade de tolerância à seca.

Apesar desta influência externa, a gastronomia moçambicana é essencialmente "vegetariana”, ou seja, proveniente do cultivo da terra. O inventário do $\mathrm{PCl}$, realizado na Mafalala, vem a confirmar este dado onde, de um total de 30 pratos registrados, cerca de $95 \%$ são feitos à base de produtos agrícolas. $E$ de entre as receitas registradas, destacam-se as entradas, pratos principais ou quentes e bebidas:

1.as entradas compreendem: salgados, doces e todo tipo de bolinho e sobremesa adocicado;

2.os pratos principais ou quentes compreendem: os molhos e pratos simples e completos;

3.as bebidas compreendem: sumo, cerveja e aguardente.

As entradas - badjia, mahanti, mahaza, tifiyose e xibubutela - são as que mais abundam na Mafalala. Algumas iguarias são preparadas por mulheres no local, sob observação do cliente, que acompanha todo o processo, como é o caso da badjias e do tifiyose. Importa referir que, logo pela manhã, as mulheres fazem-se à rua, mercados e cercanias das escolas, munidas de seus instrumentos de trabalho tais como: panela, bacia, frigideira, colher de pau, fogão, carvão, m'benga (alguidar) e, geralmente, uma mesinha para acomodar o produto a ser vendido. Cada iguaria apresenta as suas especificidades no que diz respeito aos ingredientes, simbologia e à técnica de confecção.

Falando especificamente da xibubutela, bolinho feito à base de trigo e leite de coco ralado, assado em forno de lenha, importa referir que este bolinho toma a designação xibubutela devido ao seu formato que se assemelha ao órgão sexual feminino (bubuta), eufemismo lexical, usado no sul do país para designar as partes íntimas da mulher. Conforme refere a nossa entrevistada, Ester Ernesto Makhaípe, "chama-se xibubutela por causa do seu formato, que parece vagina [risos] xibubutela é vagina" (entrevista de 02/08/2016, Mafalala).

Em relação ao valor simbólico atribuído à iguaria, Aleta Liva Muduca acrescenta:

entre os rhongas o bolo da noiva também chama-se de xibubutela. Porque é isso (bubuta) que a noiva vai servir ao seu esposo no lar [riso]. Bubuta e xibubutela são a mesma coisa. Esse xibubutela é diminuitivo de bubuta. Xibubutela é nome de antigamente. Agora aqueles bolinhos pequenos frito e assado, chamam tudo tifiyose. (Aleta Liva Muduca, entrevista de 27 /05/2017, Maputo) 
Não se sabe, porém, ao certo se a designação xibubutela está também associada à flor pepeka ou bubuta, encontrada em África, a qual é, igualmente, usada no Brasil para designar as partes íntimas da mulher (pepeka). Por se tratar de uma palavra "proibida", pelo facto de situar-se no campo do tabu linguístico (exprime falta de cortesia e desrespeito), a iguaria passou a ser genericamente apelidada por tifiyose, bolinho frito, feito igualmente à base de trigo e leite de coco ralado.

Dada a exigência na sua confecção, a produção da xibubutela tem reduzido não só na Mafalala, como também em outras regiões do país. Esta redução está associada ao elevado custo de confecção que envolve o uso de forno a lenha ou carvão, fontes cada vez mais onerosas.

Os pratos principais e quentes - xiginya xa nkakana, tihove, nimimo de mandioca, karakata, nkakana, mathapa, mbowa, nyangana, wuswa, mahati ya kuwoma ya kuhungeliwa, frango à zambeziana, entre outros - não se encontram à venda no bairro, são geralmente confeccionados para o consumo familiar e em ocasiões especiais (casamento, encontros familiares, xitique ${ }^{7}$, festivais e outros). Estes pratos, apesar de serem consumidos no quotidiano e terem uma visibilidade nos eventos locais, são pouco apreciados pela camada jovem e crianças, que os consideram "pesados", "ultrapassados" e associados aos hábitos alimentares rurais. Conforme nos elucida Ester Ernesto Makhaípe, "eu cresci a comer xiginya, minha avó e minha mãe sempre preparavam em casa, mas os nossos filhos não gostam muito, querem frango, mas quando há festas na família, todos querem comer xiginya" (entrevista de 02/08/2016, Mafalala).

Este juízo de valor depreciativo, que se faz em relação à gastronomia tradicional, tem inspirado muitos músicos moçambicanos a comporem músicas com letras que veiculam conteúdos estereotipados em relação aos pratos tradicionais. De entre vários exemplos, pode-se citar a música da conceituada cantora moçambicana, Lizha James, intitulada "Luta Entre Famílias" ([CD] Lizha James - Sentimentos de Mulher [2008], 2012): "quando vêm meus familiares/Dá-me dinheiro de couve,/Quando vêm familiares dele/Dá-me dinheiro de bife".

Como se pode depreender da estrofe acima, atribui-se um valor depreciativo aos pratos feitos à base de verdura e um status social alto aos pratos feitos à base de carne. Na mesma ordem de ideias, pode-se ler na música de António Marcos, intitulada "Maengane", a atribuição de um status baixo aos pratos temperados com amendoim ${ }^{8}$ e um status alto aos pratos temperados com óleo conforme a letra (Moniz, 2019): "enganaste-me em casa da minha mãe/Prometeste-me coisas boas/Quando na verdade me entulhas com verduras/Enquanto aos outros dás-lhes alface".

7 Xitique é uma forma de associativismo comunitário que consiste em um determinado grupo de pessoas (familiares, amigos, vizinhos ou colegas de serviço) contribuir com um valor monetário ou em espécie (alimentos, vestuário, material de construção, eletrodomésticos ou mobílias), de forma periódica (diário, semanal ou mensal). Além de ser uma forma de confraternização, o xitique é um meio de poupança, mas sem juros.

8 Os principais temperos usados na culinária moçambicana são: amendoim, castanha de cajú, amendoas de mafura (xibeé), leite de coco, entre outros. 
Nesta letra, apesar de alface ser verdura, o cantor traz no sentido figurado a ideia de que verduras (couve, mboa ou nyangana), geralmente temperadas com amendoim, traduzem um status baixo e a alface temperada com óleo um status alto.

Em relação às bebidas - xilalasana, wuputsu, ukanyi e mahewu, actualmente regista-se uma fraca apetência no fabrico e consumo na Mafalala. 0 custo de produção, a indisponibilidade da matéria-prima ${ }^{9}$ e a proliferação no mercado de bebidas industrializadas (cervejas, vinhos, refrigerantes e outras espirituosas) são alguns factores apontados que dificultam a promoção, disseminação ou o resgate das bebidas tradicionais, conforme explica Maria Cristina Pimentel:

ultimamente verifica-se uma redução no fabrico do xilalasana, dado o alto custo de vida e dos seus ingredientes. No bairro, já não são muitas as pessoas que fabricam, era comum encontrar casas com cascas de ananás nas entradas, como sinal de que nesse local havia xilalasana à venda. (Entrevista de 05/08/2016, Mafalala)

Esta redução no fabrico e consumo de xilalasana no bairro também se estende as outras bebidas como wuputsu e ukanyi, mas com excepção do mahewu. Em relação a wuputsu, a nossa entrevistada Maria Cristina Pimentel, teceu o seguinte comentário:

a preparação do wuputsu diminuiu bastante, porque esta bebida requer muito tempo e sai muito cara a sua preparação. Quando se faz, poucas pessoas consomem. Quem consome são pessoas que conhecem a bebida ( ...). As pessoas que não gostam de consumir wuputsu dizem que a bebida não engrossa, apenas enche a barriga. (Entrevista de 05/08/2016, Mafalala)

Geralmente, esse tipo de bebidas é apreciada por pessoas adultas e naturais, conhecedoras da tradição, com excepção do maheu, que é também apreciado por crianças, devido ao seu sabor adocicado e ao baixo teor de alcóol. No entanto, apesar de a xilalasana e o ukanyi não serem mais fabricados localmente, a comunidade as considera como parte do seu património cultural, devido ao valor simbólico que estas agregam nas cerimónias tradicionais, especificamente: kupalha ${ }^{10}$, lobolo ${ }^{11}$, rituais fúnebres, entre outras.

O ukanyi é uma bebida afrodisíaca e de veneração dos espíritos dos antepassados, cujo preparo e consumo obedece a certos rituais, nomeadamente: kuphahla ukanyi, xikuwha e kuhayeka mindzeko. 0 primeiro anuncia a abertura da época do canhú (makanyi), o segundo é a festa e o terceiro é o encerramento. Pelo seu carácter sagrado, o vinho do ukanyi não deve ser comercializado, pese embora as pessoas

9 As bebidas são de consumo periódico, fabricadas em função da época de cada fruto.

10 Kupalha é uma cerimónia tradicional que consiste na evocação do espírito dos antepassados. $\mathrm{Na}$ realização desta cerimónia ocorrem oferendas de bebidas e comidas aos espíritos dos antepassados, como forma de pedir o bem estar social dos sobrevivos.

11 Lobolo é o nome que se atribui a uma cerimónia de casamento considerada como tradicional, praticada sobretudo na região sul de Moçambique. Esta prática social consiste em a família do noivo oferecer bens (como bebidas, produtos alimentares e dinheiro) à família da noiva, um acto compensatório. 
pratiquem a sua venda ${ }^{12}$. Em relação ao seu valor simbólico, existem particularidades que norteiam o consumo desta bebida. A título de exemplo, o xitowatowa, derivado do ukanyi, não deve ser consumido por qualquer pessoa, sendo assim, reservado a indivíduos com um status social destacado na família e na comunidade. Importa referir que a partir do suco do canhú (makanyi) também se fabrica amarula, uma bebida industrializada e muito comercializada.

Acreditamos, portanto, que estas iguarias, quando bem aproveitadas de forma exclusiva ou como complemento de outras atracções turísticas, convertem-se em uma modalidade de turismo, de importância capital para o sector do turismo cultural, com impacto evidente no seio da comunidade.

\section{Itinerário Turístico Para Operacionalização do Turismo Gastronómico na Mafalala}

Numa primeira fase, a gastronomia por si só não poderá capitalizar o turismo no bairro. Reconhecendo o potencial do património cultural da Mafalala, propomos a criação de um itinerário, que agregue as várias atracções existentes no bairro (passeios aos locais históricos, museus, mercado, actividades lúdicas, incluindo a gastronomia).

No entanto, o sucesso deste itinerário depende, largamente, da articulação e participação consciente de vários intervenientes, na promoção e valorização da gastronomia tradicional, nomeadamente: o Estado, membros da comunidade, promotores culturais locais, guias turísticos, operadores turísticos, chefes de cozinha, restaurantes, entre outros.

A iniciativa passaria, necessariamente, pela identificação de um lugar na comunidade (centro cultural multi-uso) ou até mesmo uma residência com capacidade para albergar entre 10 a 15 pessoas. Neste local, as mulheres da comunidade, de forma organizada, poderão preparar os cardápios uma ou duas vezes por semana, para serem apreciados pelos turistas ao som do tufo ou da marrabenta, logo após a visita aos locais históricos.

Esta estratégia desafia o anonimato e a falta de exposição dos pratos principais (xiginya, tihove, karakata, kakana, mathapa, nyangana, entre outros), que ainda se encontram confinados ao espaço doméstico. $O$ confinamento destas iguarias significa o confinamento da identidade e do património alimentar dos grupos sociais da Mafalala.

\section{Considerações finais}

O turismo gastronómico é uma realidade que promove o crescimento e o desenvolvimento dos polos turísticos, sobretudo em locais onde existe uma diversidade cultural, como é o caso da Mafalala. 
Os resultados da pesquisa permitiram visualizar a dimensão do património gastronómico moçambicano no bairro (entradas, pratos principais e bebidas) que, quando bem explorado, pode transformar a Mafalala num importante destino turístico. E um esforço conjunto, aliado a uma estratégia bem articulada, pode reflectir-se em resultados mais abrangentes, não só para os operadores turísticos, como também para a comunidade, com impacto evidente na renda destes grupos. No entanto, é preciso ter atenção em relação à oferta destas iguarias à escala comercial, porque, por um lado, enquanto se amplia a visibilidade das iguarias, por outro, os pratos estarão sujeitos a inovações e adaptações como forma de agradar ao paladar do cliente, descaracterizando-as ao ponto de a comunidade detentora da receita não a reconhecer.

\section{Referências}

Capatti, A. (2006). De la guida gastronomica d'Italia au slow food: Le rôle pionnier de Italie em tourisme gastronomique. Téoros, 25(1), 19-22. https://teoros.revues.org/1307

[CD] Lizha James - Sentimentos de Mulher [2008]. (2012, 28 de agosto). Músicas de África. https:// musicasdeafrica.blogspot.com/2012/08/cd-lizha-james-sentimentos-de-mulher.html

Costa, F. R. (2009). Turismo e património cultural: Interpretação e qualificação. Senac.

Dava, F., Vilanculo, J., Tiane, C., \& Valoi, A. (2009). Ritual das primícias de ukanyi. ARPAC.

Franco, A. (2004). De caçador a goumet: Uma historia da gastronomia. Editora Senac.

Gândara J. M. G., Gimenes, M. H. S. G., \& Mascarenhas, R. G. (2009). Reflexões sobre o turismo gastrômico na perspectiva da sociedade dos sonhos. In A. Panosso Netto \& M. G. Ansarah (Eds.), Segmentação do mercado turístico (pp. 179-191). Manole.

Gimenes, M. H. S. G. (2006, julho 7-8). Património gastronómico, património turístico: Uma reflexão introdutória sobre a valorização das comidas tradicionais pelo IPHAN e a atividade turística no Brasil [Apresentação de comunicação ]. IV Seminário de Pesquisa em Turismo do MERCOSUL, Caixa do Sul.

Moniz, J. B. (2019, 24 de abril). Geração de ouro moçambique vol.1 download. JB Musik Pro. https://www. jbmusikpro.com/2019/04/geracao-de-ouro-mocambique-vol1-download.html

Müller, S. G., \& Amaral, F. M. (2012). A preservação dos saberes e fazeres gastronómicos por meio da articulação entre Instituto Federal de Educação, Ciência e Tecnologia de Santa Catarina e espaços culturais. Thema, 9(1), 1-14. https://periodicos.ifsul.edu.br/index.php/thema/article/view/92

Ndapessoa, A. (2009, 8 de fevereiro). Canhu, marula \& estórias. Missangani. http://estamosjunto.blogspot.com/2009/02/canhu-marula-estorias.html

Oliveira, N., \& Freitas, M. C. (2008). Fast food: Um aspecto da modernidade alimentar. EDUFBA. http:// books.scielo.org/id/9q/pdf/freitas-9788523209148-14.pdf

Poulain, J.-P. (2013). Sociologia da alimentação: Os comedores e o espaço social alimentar (R. C. Proença,Trad.). Editora ufsc. (Trabalho original publicado em 2002)

Santana, T. (2016). Os inventários do patrimônio alimentar brasileiro: Possibilidades para o incremento do turismo gastronômico? [Dissertação de mestrado, Universidade de Brasilia]. Repositório Institucional da UNB. https://repositorio.unb.br/handle/10482/22699

Santos, A. (2012). 0 sabor da história: Práticas alimentares e identidade quilombola. Intratextos, 3(1). https://doi.org/10.12957/intratextos.2012.3134 
Silva, S. da. (2013). O património gastronómico regional enquanto fator de valorização experiência turística: 0 caso da indústria hoteleira de cinco estrelas no Algarve [Dissertação de mestrado, Universidade do Algarve]. Sapientia. http://hdl.handle.net/10400.1/3579

Weiner, S. (2005). Manual slow food (L. Sardo, Trad.). Slow Food. 